\title{
Reduced frequency of cardiopulmonary arrests by rapid response teams
}

\author{
Redução de paradas cardiorrespiratórias por times de resposta rápida
}

\author{
Paulo David Scatena Gonçales ${ }^{1}$, Joyce Assis Polessi ${ }^{1}$, Lital Moro Bass ${ }^{1}$, Gisele de Paula Dias Santos ${ }^{1}$, \\ Paula Kiyomi Onaga Yokota ${ }^{1}$, Claudia Regina Laselva ${ }^{1}$, Constantino Fernandes Junior ${ }^{1}$, \\ Miguel Cendoroglo Neto ${ }^{1}$, Marcus Estanislao ${ }^{2}$, Vanessa Teich ${ }^{3}$, Camila Sardenberg ${ }^{1}$
}

\begin{abstract}
Objective: To evaluate the impact of the implementation of a rapid response team on the rate of cardiorespiratory arrests in mortality associated with cardiorespiratory arrests and on in-hospital mortality in a high complexity general hospital. Methods: A retrospective analysis of cardiorespiratory arrests and in-hospital mortality events before and after implementation of a rapid response team. The period analyzed covered 19 months before intervention by the team (August 2005 to February 2007) and 19 months after the intervention (March 2007 to September 2008). Results: During the pre-intervention period, 3.54 events of cardiorespiratory arrest $/ 1,000$ discharges and 16.27 deaths $/ 1,000$ discharges were noted. After the intervention, there was a reduction in the number of cardiorespiratory arrests and in the rate of in-hospital mortality; respectively, 1.69 events of cardiorespiratory arrest $/ 1,000$ discharges $(p<0.001)$ and 14.34 deaths $/ 1,000$ discharges $(p=0.029)$. Conclusion: The implementation of the rapid response team may have caused a significant reduction in the number of cardiorespiratory arrests. It was estimated that during the period from March 2007 to September 2008, the intervention probably saved 67 lives.
\end{abstract}

Keywords: Heart arrest; Cardiopulmonary resuscitation; Hospital rapid response team; Hospital mortality; Patient safety; Codes

\section{RESUMO}

Objetivo: Avaliar o impacto da implementação de um time de resposta rápida na incidência de paradas cardiorrespiratórias, na mortalidade associada à parada cardiorrespiratória e na mortalidade hospitalar em um hospital geral, de alta complexidade. Métodos: Análise retrospectiva dos eventos de paradas cardiorrespiratórias e mortalidade hospitalar, antes e depois da implementação de um time de resposta rápida. 0 período analisado compreendeu 19 meses antes da intervenção desse time (agosto de 2005 a fevereiro de 2007) e 19 meses após sua intervenção (março 2007 a setembro 2008). Resultados: No período pré-intervenção, observaram-se 3,54 eventos de parada cardiorrespiratória/1.000 altas e 16,27 mortes/1.000 altas. Após a intervenção, observou-se redução no número de paradas cardiorrespiratórias e na taxa de mortalidade hospitalar: respectivamente 1,69 eventos de parada cardiorrespiratória/1.000 altas $(p<0,001)$ e 14,34 mortes/1.000 altas $(p=0,029)$. Conclusão: A implementação do time de resposta rápida, pode ter trazido uma redução significativa no número de paradas cardiorrespiratórias. Estimou-se que, no período de março de 2007 a setembro de 2008, a intervenção provavelmente salvou 67 vidas.

Descritores: Parada cardíaca; Ressuscitação cardiopulmonar; Equipe de respostas rápidas de hospitais; Mortalidade hospitalar; Segurança do paciente; Códigos

\section{INTRODUCTION}

Success in treating cardiorespiratory arrest (CRA) depends on immediate resuscitation measures performed by trained professionals and with adequate resources ${ }^{(1)}$. The creation of specialized teams for emergency care came about with the purpose of quick and effective rescue of CRA victims. In these situations, a team of professionals (Code Blue) is activated and moves immediately to the site of the event ${ }^{(2,3)}$.

Recently, studies have shown that hours before a $\mathrm{CRA}^{(2-7)}$, adult patients present with signs and symptoms

Study carried out at Hospital Israelita Albert Einstein - HIAE, São Paulo (SP), Brazil.

${ }^{1}$ Hospital Israelita Albert Einstein - HIAE, São Paulo (SP), Brazil.

${ }^{2}$ Estanislao Training \& Solution - São Paulo (SP), Brazil.

${ }^{3}$ Medlnsight - São Paulo (SP), Brazil.

Corresponding author: Paulo David Scatena Gonçales - Avenida Albert Einstein, 627/701 - Morumbi - Zip code: $05651-901$ - São Paulo (SP), Brazil - Phone: (55 11) 2151-0608 - E-mail: paulodsg@einstein.br Received on: Mar 16, 2012 - Accepted on: Aug 7, 2012

Conflict of interest: none. 
of physiological deterioration and clinical worsening. Thus, the recognition and treatment of these factors can prevent the occurrence of CRAs and consequently, of in-hospital mortality ${ }^{(6-10)}$.

Based on this concept, in 2004 the Institute for Healthcare Improvement (IHI) recommended the implementation of rapid response teams in hospitals as part of a strategy to avoid CRAs, and consequently, to reduce in-hospital mortality. The recommendation, followed by hundreds of North-American hospitals, was part of the successful 100.000 Lives Campaign: Setting a Goal and a Deadline for Improving Health Care Quality, carried out between December 2004 and June $2006^{(2)}$.

The function of the rapid response teams, triggered by signs and symptoms of sudden and unexpected clinical worsening, is to improve the safety of hospitalized patients, providing early intervention and preventing the occurrence of CRAs ${ }^{(2-4)}$. In December 2006, a new campaign began, called The Five Million Lives Campaign, with new goals ${ }^{(11)}$.

In August 2005, Hospital Israelita Albert Einstein (HIAE) first implemented Code Blue for the treatment of adult victims of CRA. Made up by a team of two physicians (a cardiologist and a physician from intensive care or on call in the emergency room), a nurse and a physical therapist, Code Blue is set off by a single key of the telephone by any member of the treatment team $^{(12)}$.

In February 2007, 19 months after the introduction of Code Blue, the rapid response team was introduced at HIAE. Called Code Yellow, this rapid response team is triggered by the nursing team via telephone when it identifies worsening in vigilance and cardiac, neurological and respiratory monitoring parameters, or when any member of the team is seriously concerned with a patient's general status ${ }^{(13)}$. Code Yellow care is provided by a physician from the Adult Intensive Care Unit (AICU), which has up to 5 minutes to give initial treatment.

Although consistent, the concept of prevention, which is the basis for implementation of rapid response teams in hospitals, is still a debatable issue ${ }^{(9,14)}$. Many studies have failed to demonstrate a reduction in in-hospital mortality, which is its main purpose ${ }^{(15)}$.

\section{OBJECTIVE}

The objective of this study was to evaluate the impact of implementation of Code Yellow on the incidence of CRAs, on in-hospital mortality, and on CRA-related mortality.

\section{METHODS}

To evaluate the impact of the implementation of Code Yellow on the total number of CRAs, in-hospital mortality, and CRA-related mortality, a retrospective study was performed using patient medical records.

HIAE is a private general hospital focused on treating highly complex diseases, which during the period of analysis had 477 beds. During this time, 309153 patients were seen in the emergency unit (monthly average of 8136) and 13593 hospital discharges were given (monthly average of 2989).

For Code Blue, the record of treatment data was made on a specific form based on the Utstein method, in accordance with guidelines of the American Heart Association (AHA) ${ }^{(16)}$ and the Brazilian Society of Cardiology (SBC) ${ }^{(17)}$. For Code Yellow, treatment data recording was also made on a specific form, as per models suggested by the $\mathrm{IHI}^{(2)}$ (Appendix 1).

All the cases of CRA in adult patients seen at HIAE were analyzed, encompassing 19 months before and 19 months after implementation of Code Yellow. These periods were called the pre- and post-intervention periods, respectively. The initial date of analysis coincides with the date of implantation of Code Blue, which standardized treatment and collection of data relative to adult patients victims of CRA. The pre-intervention period corresponded to the interval between implementation of Code Blue, in August 2005, until the month prior to implementation of Code Yellow, in February 2007 (19 months of follow-up). The post-intervention period began in March 2007 and continued until 19 months after the implementation of Code Yellow, in September 2008.

The treatment records of the patients admitted in CRA status to the Primary Care Unit were excluded, since these patients were already in a critical situation and would not benefit from Code Yellow.

For patients that presented with CRA while in the AICU, seriousness was assessed by means of the prognostic Acute Physiology and Chronic Health Disease Classification System II (APACHE II), verified for each patient admitted to the unit ${ }^{(18)}$. If the patient had more than one APACHE score, the one considered was that closest to the CRA event.

The outcomes evaluated were cases of CRA per 1,000 hospital discharges, CRA-related deaths per 1,000 discharges, lethality of CRA cases, all-cause mortality per 1,000 discharges, and percentage of CRA-related deaths relative to the total number of all-cause deaths. CRA-related deaths were considered as those that occurred within 24 hours of the event. 
To evaluate outcomes, the following rates were constructed monthly:

- $\quad$ rate of CRAs per 1,000 discharges = (total number of CRAs/number of discharges excluding those from the day clinic, pediatrics and neonatology)*1,000;

- rate of CRA-related deaths per 1,000 discharges = (number of deaths due to CRA within 24 hours of the event/number of discharges excluding those from the day clinic, pediatrics and neonatology $* 1,000$;

- $\quad$ lethality of CRA cases $=$ (number of deaths due to CRA within 24 hours after the event/total number of CRAs);

- rate of all-cause deaths per 1,000 discharges = (total number of deaths excluding pediatrics and neonatology/number of discharges excluding those from the day clinic, pediatrics and neonatology) $* 1,000$;

- percentage of CRA-related deaths relative to the total number of all-cause deaths (number of deaths due to CRA within 24 hours after the event/total number of deaths excluding from pediatrics and neonatology).

\section{Statistical analysis}

To compare characteristics of the patients and of the preand post-intervention outcomes, exploratory analyses were performed by means of descriptive measurements. A possible statistical significance of the difference between these parameters between the pre- and postintervention periods was assessed using Student's $t$ test for non-paired samples, when normal distributions were found; otherwise, Mann-Whitney's non-parametric test was used.

To evaluate the behavior of rates over time, univariate regression models were adjusted, with Poisson distribution, stratified for the pre- and post-intervention periods, having as response variable the respective rates, and as explanatory variable the reference month of measurement. Based on the adjustments of the models, the trend coefficients and respective $\mathrm{p}$ values were obtained.

All the decisions were based on a 5\% significance level ${ }^{(19,20)}$. Statistical analyses were performed using IBM $^{\circledR}{ }^{\text {SPSS }}{ }^{\circledR}$ Statistics software.

\section{RESULTS}

During the period analyzed, 82,829 hospital discharges were recorded, 40,033 of which in the 19 months prior to implementation of Code Yellow and 42,796 during the subsequent 19 months. During this time, 214 CRAs were documented (44 outside the AICU or Stepdown Unit and 170 CRAs treated in this units), as well as 127 CRA-related deaths.

The profile of the CRA victims included in the analysis is described on table 1.

As to the characteristics of the patients that suffered CRA, no statistically significant difference was observed in the mean age pre- and post-intervention $(p=0.230)$. The mean value of the APACHE II score was 20 , during the pre-intervention period, and 26 during post-intervention $(\mathrm{p}<0.001)$, indicating greater seriousness and worse prognosis for CRA patients in the post-intervention period.

The rates of CRA per 1,000 discharges, CRA-related deaths per 1,000 discharges, lethality of CRA cases, rate of all-cause mortality per 1,000 discharges, and the proportion of CRA-related deaths relative to the total number of deaths, segmented for the pre- versus postintervention periods, are described on table 2.

The progression graph of the monthly rates of CRA per 1,000 discharges is shown in figure 1 . The dotted line represents the mean of monthly rates during the period pre-versus post-intervention.

The implementation of the rapid response team reduced by $52 \%$ the rate of CRA per 1,000 discharges $(\mathrm{p}<0.001)$. Before intervention, the CRA rate showed no significant trend towards a decline, with a trend

Table 1. Characteristics of cardiorespiratory arrest victims before and after implementing the Code Yellow (intervention)

\begin{tabular}{lccc}
\hline Characteristics & Pre-intervention & Post-intervention & p value \\
\hline Cases CRA (N) & 143 & 71 & - \\
Mean age & 73 & 68 & $0.230^{*}$ \\
Gender (\% males) & 61.43 & 52.70 & $0.306^{* *}$ \\
Mean APACHE II & 20 & 26 & $<0.001^{*}$ \\
\hline
\end{tabular}

* Mann-Whitney non-parametric test; ** Student's $t$ test.

CRA: cardiorespiratory arrest; APACHE II: Acute Physiology and Chronic Health Disease Classification System II. 
Table 2. Outcomes in the pre- versus post-intervention periods

\begin{tabular}{|c|c|c|c|c|}
\hline Outcomes & Pre-intervention & Post-intervention & Relative variation & p value \\
\hline Mean rate of $\mathrm{CRA} / 1,000$ discharges & 3.54 & 1.69 & -52 & $<0.001^{*}$ \\
\hline Mean rate of CRA-related deaths**/1,000 discharges & 2.33 & 0.78 & -66 & $<0.001^{*}$ \\
\hline Mean lethality of CRA cases & $71 \%$ & $46 \%$ & -35 & $0.015^{*}$ \\
\hline Mean rate of all-cause mortality/1,000 discharges & 16.27 & 14.34 & -12 & $0.029 * * *$ \\
\hline Mean proportion of CRA-related deaths**/number of deaths all-cause & $14.60 \%$ & $5.60 \%$ & -62 & $<0.001^{*}$ \\
\hline
\end{tabular}

* Mann-Whitney test; ** deaths within 24 hours after cardiorespiratory arrest; ${ }^{* * *}$ Student's $t$ test. CRA: cardiorespiratory arrest.

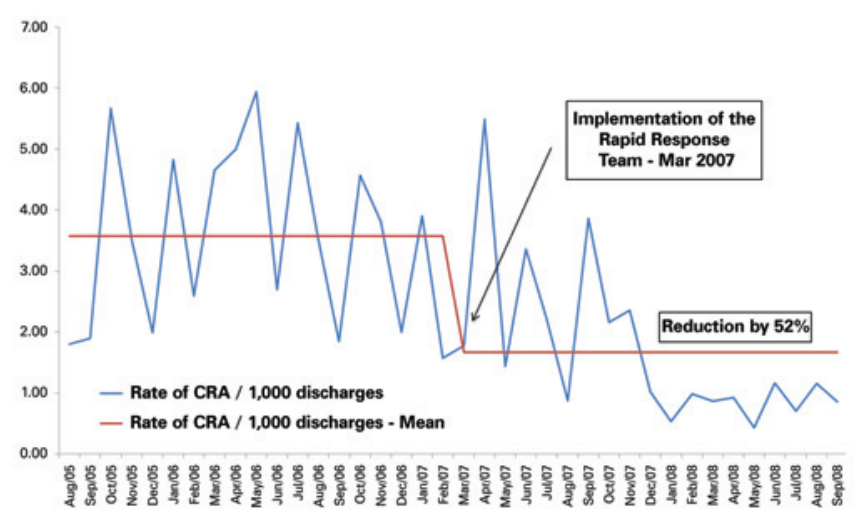

Figure 1. Evolution of cardiorespiratory arrest cases per 1,000 discharges

coefficient approximately equal to $0(\mathrm{p}=0.851)$. After intervention, this trend to decline became significant, with a trend coefficient of $-0.126(\mathrm{p}=0.0117)$.

Figure 2 shows the monthly progression of the CRA-related death rate per 1,000 hospital discharges.

As to the number of CRA-related deaths, there was a $66 \%$ reduction rate with the implementation of the

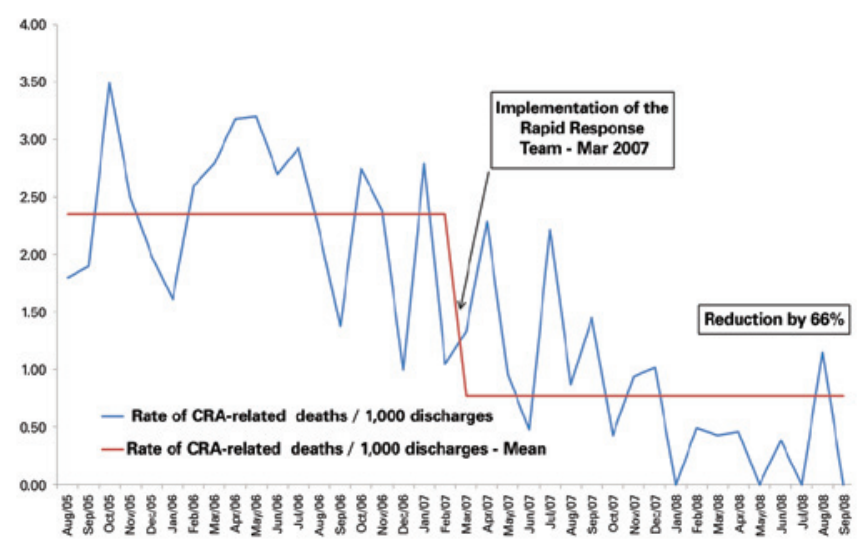

Figure 2. Evolution of the monthly rate of CRA-related deaths

rapid response team $(\mathrm{p}<0.001)$. In the trend analysis, a slight non-significant trend towards decline was noted, before intervention, probably associated with the introduction of Code Blue in August 2005 (trend coefficient $-0.032 ; \mathrm{p}=0.609)$. This trend became more accentuated and significant after intervention (trend coefficient $-0.110 ; \mathrm{p}=0.039)$.

Figure 3 shows the monthly progression of the allcause mortality rate per 1,000 discharges.

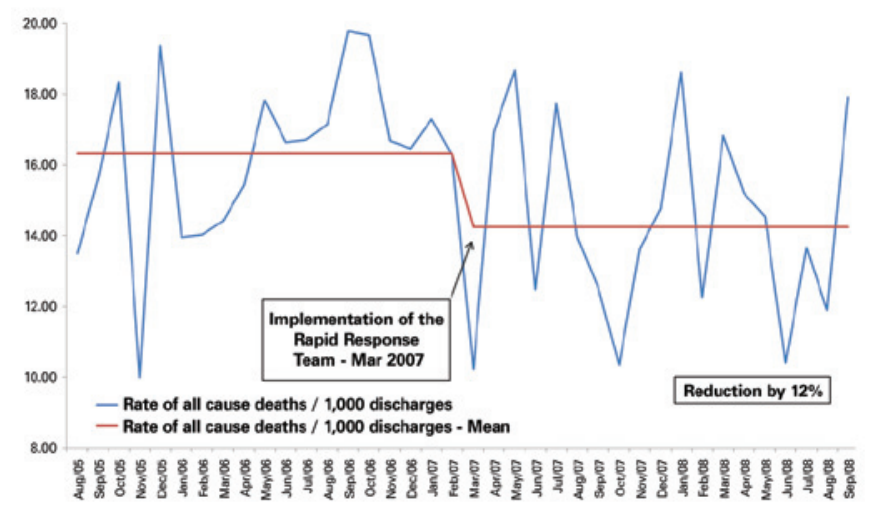

Figure 3. Evolution of the monthly rate of all-cause deaths

As to all-cause mortality, a $12 \%$ reduction was observed after the rapid response team was implemented $(\mathrm{p}=0.029)$.

\section{DISCUSSION}

After implementation of the rapid response team (Code Yellow), a 52\% drop was noted in the number of CRAs at HIAE. This decline was observed in all units of the hospital, including Intensive Therapy and Stepdown Unit. Furthermore, a significant reduction in the number of deaths associated with this event was seen, demonstrating that the rapid response teams not only reduce the incidence of CRAs, but also save lives.

The incidence of CRAs in the hospital environment is rarely published by hospitals. It is estimated that 
for every 1,000 admissions, there are 1 to 5 events. Even though it is an uncommon complication during hospitalization, the rates of morbidity and mortality associated with the event are enormous, varying between 80 and $85 \%$.

Even with modern cardiopulmonary resuscitation techniques and intensive training, little has changed as to the outcomes most often associated with this event: death, prolonged hospitalization, and neurological sequelae. Studies have shown that during hospitalization in general hospitals patients present with signs and symptoms of physiological deterioration a few hours before suffering a CRA, suggesting that strategies for early identification and treatment are able to improve the outcome for these patients ${ }^{(22-24)}$. Based on this hypothesis, the implementation of the medical emergency teams (MET), also called rapid response teams (RRT), was the intervention adopted by various hospitals with the objective of reducing the incidence of CRAs, unplanned admissions to ICUs, and primarily, reducing in-hospital mortality. More than taking on care of the patient, the rapid response teams work primarily as an immediate second opinion in potentially serious cases $^{(7,9,25,26)}$. In this way, the presence of professionals adequately prepared for these situations is a critical factor for success.

The controversy regarding the subject comes from the lack of multicentric randomized studies ${ }^{(14)}$. A metaanalysis conducted by Chan et al. in 2010 concluded that although they have great appeal, there is no robust evidence showing that rapid response teams are effective in reducing in-hospital mortality ${ }^{(15,27)}$.

\section{Primary findings}

This is the first study to analyze the impact of the introduction of a rapid response team in the country, and one of the longest follow-up periods described in literature. In the 19 months prior to the implementation of Code Yellow, the rate of CRA-related deaths (that occurred within 24 hours after the event) was 2.33 per 1,000 discharges. Making a projection, if the CRArelated deaths remained on the same level, 100 CRArelated deaths would be expected during the postintervention period (2.33 deaths/1,000 discharges $\mathrm{x}$ 42,796 discharges). As 33 deaths were reported during that period, in the 19 months after its implementation Code Yellow may have saved 67 lives.

Another important finding concerns lethality. After intervention, the CRA became a less lethal event. When the seriousness and prognosis were analyzed by means of APACHE II of the patients hospitalized in the ICU who suffered a CRA, it was noted that, even though they were more serious and had a worse prognosis, the number of CRA-related deaths in these patients was lower.

\section{Limitations}

The study data do not allow one to affirm a cause and effect relation between implementation of the rapid response team and the reduction of in-hospital mortality, since other strategies focused on patient safety were implemented at HIAE during this same period. Additionally, the benefit of implementation of the rapid response team may be associated not only with early intervention, but also with the capacity acquired by the team in rapid recognition of signs and symptoms of clinical deterioration ${ }^{(9)}$. Thus, it is likely that the continued training of the team, advances in resuscitation techniques, and greater availability of resources also contributed toward the outcome observed.

\section{CONCLUSION}

Although there may be a strong probability of reduction in the incidence of CRA, of in-hospital mortality, and of associated mortality by the implementation of a rapid response team, the limitations of the study do not allow this assertion. New studies are necessary to solve this controversy.

\section{ACKNOWLEDGMENTS}

Out thanks to the Code Blue and Code Yellow teams and to Dr. Jacyr Pasternak.

\section{REFERENCES}

1. Hazinski MF, Nolan JP, Billi JE, Böttiger BW, Bossaert L, de Caen AR, Deakin CD, Drajer S, Eigel B, Hickey RW, Jacobs I, Kleinman ME, Kloeck W, Koster RW, Lim SH, Mancini ME, Montgomery WH, Morley PT, Morrison LJ, Nadkarni VM, O'Connor RE, Okada K, Perlman JM, Sayre MR, Shuster M, Soar J, Sunde K, Travers AH, Wyllie J, Zideman D. Part 1: executive summary: 2010 International Consensus on Cardiopulmonary Resuscitation and Emergency Cardiovascular Care Science With Treatment Recommendations. Circulation. 2010;122(16 Suppl 2):S250-75.

2. Berwick DM, Calkins DR, McCannon CJ, Hackbarth AD. The 100,000 lives campaign: setting a goal and a deadline for improving health care quality. JAMA. 2006; 295(3):324-7.

3. Offner PJ, Heit J, Roberts R. Implementation of a rapid response team decreases cardiac arrest outside of the intensive care unit. J Trauma. 2007; 62(5):1223-8; discussion 1227-8.

4. Hillman K, Chen J, Cretikos M, Bellomo R, Brown D, Doig G, Finfer S, Flabouris A; MERIT study investigators. Introduction of the medical emergency team (MET) system: a cluster-randomised controlled trial. Lancet. 2005; 365(9477):2091-7.

5. Iyengar A, Baxter A, Foster AJ. Using Medical Emergency Teams to detect preventable adverse events. Critical Care. 2009;13(4):R126. 
6. Skrifvars MB, Nurmi J, Ikola K, Saarinen K, Castren M. Reduced survival following resuscitation in patients with documented clinically abnormal observations prior to in-hospital cardiac arrest. Resuscitation. 2006;70(2): 215-22.

7. Jone D, Bellomo R, DeVita MA. Effectiveness of Medical Emergency Team: the importance of dose. Critical Care. 2009;13(5): 313.

8. Chugh SS. Early identification of risk factors for sudden cardiac death. Nat Rev Cardiol. 2010;7(6):318-26.

9. Jones DA, DeVita MA, Bellomo R. Rapid-Response Team. N Eng J Med. 2011;365(2):139-46.

10. Moulaert VRMP, Verbunt JA, van Heugten CM, Bakx WGM, Gorgels AP, Bekkers SC, et al. Activity and life after survival of a cardiac arrest (ALASCA) and the effectiveness of an early intervention service: design of a randomised controlled trial. BMC Cardiovasc Disord. 2007;7:26.

11. Institute for Healthcare Improvement (IHI). 5 Million Lives Campaign. Getting started kit: rapid response teams [Internet]. Cambridge, MA: Institute for Healthcare Improvement; 2008. [cited 2012 Set 8]. Available from: www.ihi.org

12. Hospital Israelita Albert Einstein. Políticas Institucionais Enfermagem. Atendimento de Parada Cardio-Respiratória: Código Azul [política institucional]. [criado 2005 ago 16; versão eletrônica atualizada 2011 out; responsáveis: Claudia Regina Laselva, Adriana da Silva Pereira, Carla Fátima de Paixão Nunes].

13. Hospital Israelita Albert Einstein. Políticas Institucionais Enfermagem. Atendimento a emergências, urgências, intercorrências e avaliações médicas de pacientes no HIAE-Morumbi - código amarelo adulto. [política institucional]. [criado 2005 ago 16; versão eletrônica atualizada 2011 dez; responsáveis Anna Margherita G. T. Bork, Simone Mutti Mayer, Adriana da Silva Pereira, Carla Fatima de Paixao Nunes].

14. Winters BD, Pham J, Pronovost PJ. Rapid response team-walk, don't run. JAMA. 2006;296(13):1645-7.

15. Chan PS, Jain R, Nallmothu BK, Berg RA, Sasson C. Rapid Response Team: A Systematic Review and Meta-Analysis. Arch Intern Med. 2010;170(1): 18-26.

16. Jacobs I, Nadkarni V, Bahr J, Berg RA, Billi JE, Bossaert L, Cassan P, Coovadia A, D’Este K, Finn J, Halperin H, Handley A, Herlitz J, Hickey R, Idris A, Kloeck W, Larkin GL, Mancini ME, Mason P, Mears G, Monsieurs K, Montgomery W, Morley P, Nichol G, Nolan J, Okada K, Perlman J, Shuster M, Steen PA, Sterz F, Tibballs J, Timerman S, Truitt T, Zideman D; International Liaison Committee on Resuscitation; American Heart Association; European Resuscitation Council; Australian Resuscitation Council; New Zealand Resuscitation Council; Heart and Stroke Foundation of Canada; InterAmerican Heart Foundation; Resuscitation Councils of Southern Africa; ILCOR Task Force on Cardiac
Arrest and Cardiopulmonary Resuscitation Outcomes. Cardiac arrest and cardiopulmonary resuscitation outcome reports: update and simplification of the Utstein templates for resuscitation registries: a statement for healthcare professionals from a task force of the International Liaison Committee on Resuscitation (American Heart Association, European Resuscitation Council, Australian Resuscitation Council, New Zealand Resuscitation Council, Heart and Stroke Foundation of Canada, InterAmerican Heart Foundation, Resuscitation Councils of Southern Africa). Circulation. 2004;110(21):3385-97.

17. Sociedade Brasileira de Cardiologia. Diretriz de apoio ao suporte avançado de vida em cardiologia - código azul - registro de ressuscitação. Normatização do carro de emergência [Internet]. Arq Bras Cardiol. 2003 [citado 2012 Set 8]; 81 (Supl 4):[cerca de 14 p.]. Disponível em: http://www.scielo.br/pdf/abc/ v81s4/20229.pdf

18. Knaus WA, Draper EA, Wagner DP, Zimmerman JE. APACHE II: a severity of dsease classification system. Crit Care Med. 1985;13(10):818-29.

19. Bussab WO, Morettin PA. Estatística básica. 5a ed. São Paulo: Saraiva; 2003.

20. Hollander M, Wolfe DA. Nonparametric statistical methods. New York: Wiley; 1999.

21. Sandroni C, Nolan J, Cavallaro F, Antonielli M. In-hospital cardiac arrest: incidence, prognosis and possible measures to improve survival. Intensive Care Med. 2007;33(2):237-45.

22. Buist MD, Jarmolowski E, Burton PR, Bernard SA, Waxman BP, Anderson J. Recognising clinical instability in hospital patients before cardiac arrest or unplanned admission to intensive care. A pilot study in a tertiary-care hospital. Med J Aust. 1999;171(1):22-5.

23. DeVita MA, Bellomo R, Hillman K, Kellum J, Rotondi A, Teres D, et al. Findings of the first consensus conference on medical emergency teams. Crit Care Med. 2006;34(9):2463-78.

24. Buist MD, Moore GE, Bernard AS, Wazman BP, Anderson JN, Nguyen TV. Effects of a medical emergency team on reduction of incidence of and mortality from unexpected cardiac arrests in hospital: preliminary study. BMJ. 2002;324(7334):387-90.

25. Hillman K, DeVita M, Bellomo R, Chen J. Comments and opinions. Metaanalysis for rapid response teams. Arch Intern Med. 2010;170(11):996-7. author reply 997.

26. Breger KS, Afasarmanesh N, Galindo MS. Prevention of complications in hospitalized patients. Part VII: Cardiac arrest. Proceding of UCLA Healthcare [internet]. 2008 [cited 2012 Set 8]; 12: [about 7p.]. Available from: http:// www.med.ucla.edu/modules/wfsection/article. php?articleid $=398$

27. Chan PS, Khalid A, Longmore LS, Berg RA, Kosiborod M, Spertus JA Hospital-wide code rates and mortality before and after implementation of a rapid response team. JAMA. 2008;300(21):2506-13. 
Appendix 1. Form to register care to adult patients in emergency and urgency - Yellow Code - based on the model by the Institute for Healthcare Improvement

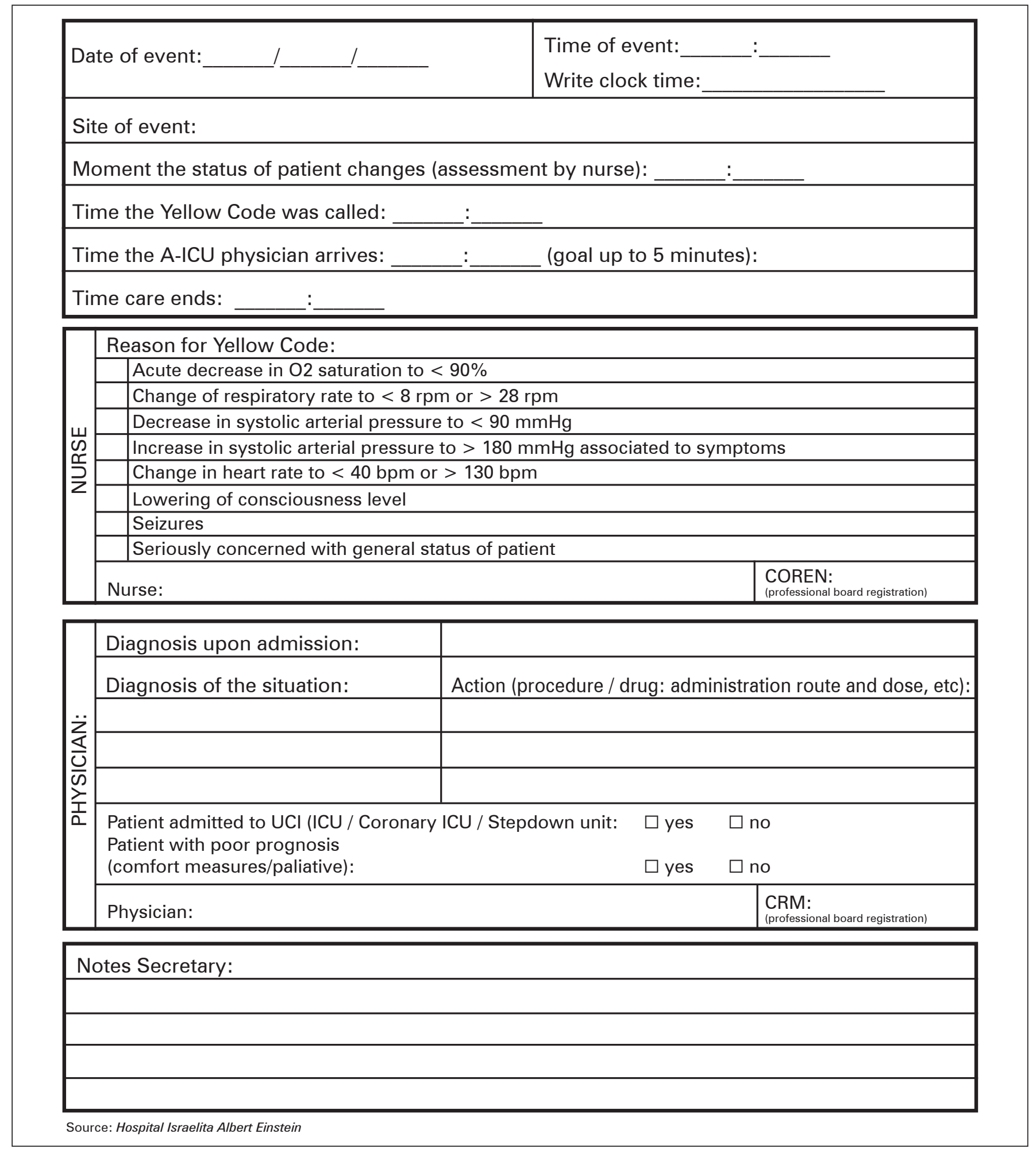

